\title{
La vieja historia del Museo de Arte Moderno
}

\author{
Elena Vozmediano
}

\section{EL DECRETO}

El Museo de Arte Moderno, abuelo de nuestro Museo Nacional Centro de Arte Reina Sofía, de interminable nomenclatura, fue creado por Real Decreto el 7 de agosto de 1894, gestionado por el Ministerio de Fomento - cuyo titular era Alejandro Groizard-, a través de su Negociado de Bellas Artes, y con la reglamentaria aprobación de la reina regente, María Cristina. En el decreto se establecia a grandes rasgos cuáles serian las obras que iban a formar parte del museo, la plantilla -con sus sueldos-, y los cauces de financiación; en las Disposiciones Transitorias se nombraba la comisión que se encargaría de organizar la instalación del mismo '. La retórica propia de este tipo de documentos no impide que encontremos en él sabrosa información acerca del tipo de institución que se preparaba y acerca de las motivaciones que llevaron a sus promotores a emprender un proyecto que ya desde su mismo enunciado se revelaba muy problemático. Tanto, que nacía sin presupuesto. En el decreto se hace gala de un optimismo a toda prueba a este respecto:

"Los gastos que originan los servicios que se crean de custodia y conservación del Museo contemporáneo iban incluidos en los presupuestos últimamente presentados a las Cortes. La no aportación de

\footnotetext{
' Real Decreto de agosto de 1894, La Gaceta de Madrid, año 233, núm. 219, págs. 480 y 481 .
} 
esos presupuestos no ha parecido, sin embargo, al Ministro de Fomento obstáculo insuperable para proceder desde luego a la instalación del Museo.

"Los empleados del Museo Nacional y los funcionarios de instrucción pública correspondientes al Negociado de Bellas Artes, llevados de su celo, llenarán desinteresadamente y con carácter interino aquellas atenciones, hasta que puedan hacerse los nombramientos definitivos en el próximo año económico".

En principio se prevé que haya adquisiciones de obras, siempre a través de los conductos institucionales, aunque ya en varias ocasiones se hace mención de que se preferirian las donaciones de los artistas. Se confía por lo tanto en el desinterés de todos los participantes en la puesta en marcha del museo. No es de extrañar, en estas condiciones, que transcurriesen cuatro años, a partir de la publicación del decreto, hasta la apertura del establecimiento.

Cuando se especifica qué obras constituirán sus fondos, observamos que se trata siempre de arte oficial e institucionalizado: el adquirido en las Exposiciones Nacionales y a través de la Academia de Bellas Artes en Roma, y las que recomiende la Academia de Bellas Artes de San Fernando en Madrid; de la misma procedencia habia de ser el conservador: un artista premiado en las Exposiciones o pensionado en Roma. Además de Pedro de Madrazo, figura clave en las instituciones artísticas españolas y director de la Sección de Pintura de la Academia de San Fernando, integran la comisión Federico Balart, Jacinto Octavio Picón, Carlos Groizard, Vicente Palmaroli, director del Museo Nacional de Pintura y Escultura, y Álvarez, secretario del mismo; y como secretario, un oficial del Negociado de Bellas Artes, Leandro J. Puente y Llovet. Difícilmente podría configurarse un plantel menos susceptible de sorpresas.

Las razones oficiales para la creación del museo se expresan en el real decreto: en primer lugar se impone la urgencia de acondicionamiento y clasificación de las obras, tareas que, como veremos en lo referente a la procedencia de los fondos, eran de primera necesidad. Pero detrás de esta aparentemente inocente labor de traslado, se esconde otra motivación que afecta a la misma valoración del arte de aquel momento y que ponia en entredicho la actividad de mecenazgo que venía desempeñando el estado desde hacia décadas: las pinturas contemporáneas no soportaban la comparación con las pinturas antiguas, vecinas suyas en el Museo del Prado en el momento en que se publica el decreto. Se impone el sentimiento de derrota y lo único que les queda es afirmar los tradicionales valores del pueblo español, entre los cuales está el de la excelen- 
cia artística, que saldrá finalmente airoso del trance ${ }^{2}$. Confiando en este genio en potencia, se trata de fomentar su desarrollo, para el que el ministerio parece creer tener la receta infalible: fomentar la comparación, que hace brotar el juicio y el culto de lo bello; las ideas de los artistas -no especifica si estéticas o morales- llegarán y se encarnarán así en la opinión, con cuyo apoyo podrá el artista realizar obras duraderas. Se trasluce aqui la dependencia del artista respecto al gusto no instruido en materias artísticas y su reclusión en la modalidad de arte educativo que perseguía la jerarquía artística.

A pesar de los pesares no hay que restarle mérito al deseo de los gobernantes de dar digno alojamiento a las obras de arte que había producido el siglo, pero si conviene profundizar un poco en las motivaciones que pueden conducirles a comprometerse en el considerable desembolso, aunque pospuesto, que iba a suponer la instalación del museo. Por otra parte, y aqui llegamos, en mi opinión, al centro de la cuestión, se puede decir que los fondos del museo son «obra» del estado: primero a través de la influencia de la Academia de San Fernando y su sucursal en Roma, y luego por las Exposiciones Nacionales. Así, creando un Museo de Arte Moderno, el gobierno está institucionalizando una apología del papel de protector de las artes que ha tenido el estado a lo largo del siglo.

\section{LOS FONDOS DEL MUSEO}

He intentado seguir la pista a las obras que se presentaron en el catálogo de apertura del museo para confirmar las indicaciones que se nos hacen acerca de su procedencia, pero tal persecución ha resultado laberíntica y poco fecunda. El punto de partida ha de situarse en la colección que se conservaba en el convento de la Trinidad, que habia pasado al Prado en 1872. Dado que el Museo de la Trinidad no se desmanteló hasta 1870, tuvo tiempo de acoger las compras que se efectuaron en las Exposiciones Nacionales hasta esa fecha. Gaya Nuño recoge la catalogación que Gregorio Cruzada Villaamil, director del museo

${ }^{2}$ "[...] la colección de cuadros y esculturas debidas al genio, nunca inactivo, de nuestros artistas, y organizar el Museo de Arte Contemporáneo, que ha de alestiguar una vez más que no decaen en una raza las innatas condiciones y las excepcionales aptitudes que dieron en los pasados siglos días de gloria al arte nacionalm. Real Decreto. 
entre 1862 y 1864 , hizo en ese periodo ${ }^{3}$. En ella se mencionan, según Gaya Nuño, 760 cuadros contemporáneos, calificados de "malísimos", pero no se catalogan, porque Villaamil sólo incluyó en su elenco aquellos cuadros que él consideraba de calidad (590 de 1.739 en total).

La situación de todos estos cuadros, y los que se añadieron entre 1872 y 1898 - fecha en que se abrió el Museo de Arte Moderno-, en el Museo del Prado era lamentable: formaban una especie de colección aparte que ni siquiera se catalogaba con las pinturas antiguas, poniéndose así de manifiesto la provisionalidad de su alojamiento. Existe un catálogo de los pintores contemporáneos del Prado (Museo Nacional de Pintura y Escultura entonces), publicado por Carlos Martínez y Emilio Ruiz Cañabate en 1889, que sólo recoge 306 cuadros, reduciendo a menos de la mitad la cantidad apuntada por Villaamil. Es posible que, cuando se trasvasó el Museo de la Trinidad, muchos cuadros se repartieran por provincias, o quedaran almacenados en alguna parte ${ }^{4}$. El resto pasó por sótanos, despachos, iglesias, sanatorios, y escuelas, y supongo que una gran parte de esos desterrados fueron de los contemporáneos. Esto no fue una novedad, Vicente Poleró denuncia ya esta práctica en 1868, antes del traslado ${ }^{5}$, y Francisco María Tubino hace un relato bastantes espeluznante de la suerte que corrieron los fondos de la Trinidad en el Prado ${ }^{6}$.

Sabemos que en 1894, cinco salas del museo eran ocupadas por la pintura contemporánea porque así se menciona en el real decreto de creación del Museo de Arte Moderno. He comparado la relación de Ruiz Cañabate con el catálogo del Museo de Arte Moderno de 1899 y, ade-

${ }^{3}$ Gaya Nuño, J.A., «El Museo Nacional de la Trinidad. Historia y catálogo de una pinacoteca desaparecida", Boletín de la Sociedad Española de Excursiones, 1947, págs. 19-77.

4 Sabemos que de los 1.739 cuadros del Museo de la Trinidad, sólo un centenar de ellos pasaron al catálogo del Prado.

5 POLERO y TOLEDO, V., Breves observaciones sobre la utilidad y conveniencia de reunir en uno solo, los dos museos de pintura de Madrid, y sobre el verdadero estado de conservación de los cuadros que constituyen el Museo del Prado. Madrid 1968, págs. 6-7.

6 "Si en la Pinacoteca madrileña nuestra pintura se presentó acéfala, tampoco hasta ahora se pensó en completarla con los autores modernos y contemporáneos. Un esperado siniestro, hizo ver la inconveniencia de conservar hacinados los lienzos del antiguo Museo nacional, en las Covachuelas del ministerio de Fomento: la elocuencia de un incendio y el argumento de varios cuadros destruidos, impulsó a la administración a disponer fuesen trasladadas al Prado las obras de más mérito; al Prado llegaron, pero no para ser expuestas: sobre ochenta lienzos esperan la luz encerrados en las salas flamencas y holandesa, [...]" - aunque añade en una nota: "Parece que en el tiempo transcurrido desde que se escribio este artículo ha sufrido alguna reforma el Museo por lo que toca a estos extremos". TUBINo, F. M., "Crítica artística: El museo del Prado, la Academia de Bellas Artes y el catálogo del señor Madrazo", Revista de España. Madrid 1972, año 5, núm. 116, pág. 516. 
más de constatar la gran cantidad de cuadros que se compraron en diez años, más de cien, he comprobado que en el segundo faltan cuadros respecto al primero, en la considerable cantidad de 44. Dudo mucho que esas obras se quedasen en el Prado, puesto que allí no quedaba ya pintura del XIX a partir de Goya; también creo que se tratara de una selección de calidad, puesto que algunos de los cuadros "perdidos" pertenecían a autores que tuvieron obras en el Museo de Arte Moderno, de similar tamaño $y$, a veces, tema.

Tomando también como base el catálogo de 1899, el primero que se editó tras la apertura del museo, he hecho un recuento por artistas que arroja resultados que creo significativos: de los 202 pintores que se reúnen en la sección de pintura, 156, aproximadamente tres cuartos del total, son artistas premiados en las Exposiciones Nacionales, 25 han muerto y no se recoge su participación en los premios de las Exposiciones y 14 son extranjeros. Salta a la vista que la gran mayoria de las obras que irían después al Museo de Arte Moderno fueron adquiridas con motivo de las Exposiciones y que el Museo de Arte Moderno fue fundamentalmente el museo de los premios de las mismas. Para la primera mitad del siglo quedan esos 25 pintores ya fallecidos que, por otra parte, aparecen casi siempre en el catálogo como integrados en el sistema artístico de la Academia de Bellas Artes de San Fernando y sucursales. Sin embargo, no sería justo dejar de ver en ello una faceta muy positiva: se podría decir que el de Arte Moderno es un museo de pintores vivos.

\section{LA UBICACIÓN DEL MUSEO Y LOS PROBLEMAS DE ESPACIO}

Como hemos visto, habia una razón meramente práctica para la creación de un Museo de Arte Moderno: el reunir en un sólo lugar la colección de arte contemporáneo español, en malas condiciones de conservación y accesibilidad por parte del público. Se disponía por fin de un espacio para ello. Este había sido uno de los mayores obstáculos para toda iniciativa de museo desde que, tras las desamortizaciones, se acentúa en España el problema de la conservación y exhibición del patrimonio artístico. La construcción del Palacio de Biblioteca y Museos supuso por ello un gran avance, un primer paso en la gestación de una sensibilidad por los problemas específicos del patrimonio por parte de la clase política española. Pero el esfuerzo fue a todas luce insuficiente. En la consulta que por requerimiento de Pedro de Madrazo se hace al arquitecto Antorio Ruiz de Salies sobre la nueva distribución de salas en dicho edificio, 
éste resume la problemática que planteaba la reunión en un solo edificio, aunque de grandes proporciones, de varios museos, que fueron finalmente más de los que inicialmente se había pensado:

"La falta de local suficiente para el Museo de Arte Moderno, comprendiendo en él las obras de Pintura y Escultura, proviene de haberse variado completamente la distribución del edificio de Bibliotecas y Museos Nacionales respecto a la acordada y aprobada en el proyecto que sivió para la conclusión del mismo. En éste sólo se habia contado con el establecimiento de Biblioteca Nacional, Museo Arqueológico y Arte Moderno. A consecuencia de reclamaciones del Señor Director de la Biblioteca Nacional se varió notablemente la distribución proyectada, y se dió además cabida en el edificio al Archivo Histórico y últimamente al Museo de Historia Natural. El ensanche concedido a la Biblioteca Nacional y a estos dos últimos establecimientos ha sido todo a expensas del local destinado al Arte Moderno, que ha quedado sin el que debía ocupar la Escultura, y con superficie relativamente muy reducida para la Pintura" ?.

Cuando el Museo de Arte Moderno iba a proceder a instalarse, ya lo habían hecho todos los demás, por lo que tuvo que aceptar el espacio que se le había dejado, no pudiendo elegir las salas que hubieran sido más apropiadas para su propósito. Le correspondian algunas de la fachada a la calle Recoletos, en su planta principal, o primera. La Comisión se encontró con que el espacio era evidentemente insuficiente para acoger las obras que constituían los fondos del museo. En la misma carta de abril de 1896 el Arquitecto Director propone a instancias de Pedro de Madrazo unas cesiones de salas entre los distintos centros que ocupan el edificio que repercutieran en una mayor holgura para el museo, modificaciones que serian aceptadas por el Ministerio en buena parte. La Biblioteca Nacional cede al Museo de Arte Moderno cinco salas y parte de otra como talleres, terminando por fin con las reiteradas peticiones de Madrazo de que le fuesen concedidas salas para este fin.

Aun cuando los criterios de exposición eran entonces muy diferentes de los que rigen hoy, y no se tenía ningún empacho en colocar unos cuadros encima de otros ni en rellenar los huecos con cuadros pequeños, casi desde el techo hasta el suelo, la abundancia de cuadros de enormes

1 El Arquitecto Director, Antonio Ruiz de Salies al llustrísimo Director General de Instrucción Pública. 8 de abril de 1986. Documento inédito, conservado en el Archivo General de la Administración en Alcalá de Henares. 
dimensiones, impuestas por el afán de conseguir los premios en las $\mathrm{Na}$ cionales, agravaba el problema de espacio, y en las imágenes que conservamos de las dos primeras salas del museo, publicadas por La Ilustración Española y Americana, los cuadros aparecen especialmente apiñados ${ }^{8}$.

La documentación que se conserva en el Archivo General de la Administración consiste en buena parte en las cartas de Pedro de Madrazo requiriendo espacios más adecuados para el museo que los que se le habian concedido. El más urgente de obtener era el que debía destinar a taller de restauración, en el que se llevarían a cabo las tareas previas a la colocación de los cuadros, de las cuales no se podia, a juicio de Madrazo, prescindir ${ }^{9}$. Este espacio no habia sido previsto en la adjudicación de salas, y Madrazo tuvo que solicitarlo insistentemente durante años para que finalmente le fuera concedido, como vimos antes, regateando a la Biblioteca Nacional habitaciones fronterizas.

A pesar de todos los esfuerzos de Madrazo, y a que se le hicieran algunas mínimas concesiones, el ámbito en el que finalmente pudo abrirse el museo era definitivamente insuficiente. Asi lo vieron en La Ilustración Española y Americana cuando se reseñó la apertura.

"Con gran estrechez y a duras penas se han podido colgar allí las obras artísticas adquiridas por el Estado para el Museo Nacional, y no acertamos a explicarnos dónde han de colocarse las que en lo sucesivo merezcan el mismo honor.

«Y si el Museo que se acaba de organizar ha de responder al doble objeto de conservar las mejores obras que el arte va produciendo y de facilitar el estudio a cuantos a él se dedican, preciso será que en el piazo breve se le dé mayor ensanche, utilizando otras salas de la planta principal dotadas de luz apropiada para el objeto, y que, en el deseo de acumular en el espacioso edificio más de lo que en su recinto puede tener cabida, han sido destinadas a dependencias que, por su índole, no necesitan locales de esas especiales condiciones" ${ }^{10}$.

- La llustración Española y Americana, núm. XXX, 15-8-1898 pág. 84 y núm. XLIII, 22 11-1898, pág. 291.

${ }^{9}$ Cartas de Pedro de Madrazo al Ministro de Fomento, 28 de marzo y 8 de julio de 1896. Inéditas, Archivo General de la Administración.

10 Anónimo: "Madrid: Museo de Arte Moderno", La llustración Española y Americana, núm. XXX, 15-8-1898, pág. 83. 


\section{LA ORDENACIÓN DE LAS OBRAS}

Una vez reconocido el desolador panorama geográfico, la comisión tuvo que plantearse la estrategia de ataque, esto es, el criterio de exposición. Ríos de tinta habian corrido sobre la función educativa de los museos y sobre la importancia de una buena disposición de las obras, racional, que permitiese lo que parecia ser la principal función de su agrupación: la comparación. Se había criticado la ordenación de las pinturas del Museo del Prado, y todo el mundo parecia tener una opinión al respecto. Dos de los futuros miembros de la comisión para el Museo de Arte Moderno habian escrito, anteriormente a su nombramiento, sendos artículos periodísticos en los que hacian propuestas en este sentido.

José Octavio Picón publicó en El Eco Moderno, en 1877, un interesante recuento de los criterios museísticos en boga, preocupándose, con una concepción que considero avanzada, de la responsabilidad del arquitecto en la disposición e iluminación de las salas. En cuanto a la ordenación, debe quedar reflejada en la colocación de los cuadros y en el catálogo. Dos son los métodos más habituales: el cronológico y el de escuelas. Tras exponer brevemente en qué consiste cada uno, se pronuncia a favor del criterio por escuelas, "[...] no admitiendo la existencia de estas sino cuando sean verdaderas expresiones de un ideal artístico nuevo con relación a los anteriormente conocidos, y proceder a la colocación de las obras de cada escuela por riguroso orden de fechas" ${ }^{11}$. En 1895, cuando ya se debía estar discutiendo en la comisión cuál iba a ser la ordenación, Picón escribe, con motivo de la Exposición del mismo año, un artículo sobre la evolución del arte español ${ }^{12}$. En él esboza algo parecido a una clasificación por escuelas: "Las tendencias neo-clásicas al modo francés, importadas por $D$. José de Madrazo, y el sentido romántico, cuyos orígenes tampoco eran españoles, en que se inspiró su hijo Federico, fueron compenetrándose y modificándose según las condiciones, facultades y tradición que nos eran propias, hasta crear, si no una verdadera escuela, a lo menos un núcleo de artistas animados por ideas comunes". De la primera tomaron el respeto al dibujo y de la segunda el sentimiento poético. En esta escuela incluye a Gisbert, Palmaroli, Vallés y Rosales, y dice que su género es el histórico. "Pasan

"PICON, J. O., "Lo que debe ser un museo de pinturas", El Eco Moderno, núm. 7 , 21-6-1877, pág. 1.

${ }^{12}$ PICON, J. O., “Exposición Nacional de Bellas Artes de 1895. Impresión general. De 1856 a 1895". Historia y arte, núm. 4, Madrid 1895, págs. 57-62. 
algunos años y la influencia de Fortuny modifica la marcha de la pintura. [...] él contribuyó mucho a que la ejecución tuviera la importancia que merece; [...]". Señala que, sin embargo, siguió cultivándose la pintura de historia y finaliza su recorrido diciendo que "Por fín, en la pasada exposición de 1892 pareció iniciarse un movimiento favorable a la pintura de costumbres. En la de 1895, esa tendencia, esa inclinación, es indudable: [...]». Picón se muestra más comprensivo ante esta nueva dirección que Madrazo, como veremos, y llega a decir, que puede haber cuadro sin idea pero no cuadro sin forma, aunque critica la temática tremendista que tratan los nuevos pintores.

En 1893, Federico Balart, miembro de la comisión, publica en El Imparcial un artículo en el que habla de la colocación y catálogo del Museo del Prado. Es muy interesante por la descripción que hace del "criterio" que se había seguido en la distribución de los cuadros:

"Casi todos los departamentos están dispuestos con la esmerada simetria que de ordinario se procura y pocas veces se logra para el arreglo de un salón particular; en cada pared un cuadro grande ocupando el centro; a sus lados, en perfecta correlación, otros cuyos tamaños y asuntos armónicamente se corresponden; a un retrato hace pareja otro retrato de las mismas o muy aproximadas dimensiones; a un país otro país, a un florero, otro florero; hasta la tonalidad se ha intentado $y$ casi siempre conseguido equilibrar. Asombra calcular la memoria, la paciencia y el tiempo necesarios para llegar a esa perfecta regularidad que acreditaria la competencia del más consumado adornista" ${ }^{13}$.

Balart se manifiesta, lógicamente, contrario a este criterio, ya que “...el fin de tales dispendios es proporcionar al artista, al crítico, al historiador, al antropólogo, documentos interesantes para el progreso de sus habituales estudios". Y «Si nuestro Museo fuera lo que reza su nombre..." debería estar ordenado cronológicamente, “...por épocas, por naciones y por escuelas". Esto, que parece muy razonable, no lo es tanto cuando en la segunda parte del artículo dice que como el museo tiene "...hasta el exceso..." cuadros de los más ilustres y los menos ilustres pintores, "Eso permite combinar a un mismo tiempo las obras de distintas maneras, en departamentos distintos, ya por escuelas, ya por analogías de asunto, de composición, de estilo y de otras circunstancias dignas de consideración en cada caso, siempre que con ello se faciliten y 1893.

${ }^{13}$ BALART, F., "Algo sobre el Museo de Pinturas", El Imparcial. Madrid, 25-9 y 30-9- 
provoquen comparaciones a propósito para notar semejanzas y diferencias entre las que merezcan particular confrontación". Además, los cuadros dudosos deberían colgarse junto a aquellos que puedan, por comparación, solucionar el problema. Pueden seguirse también criterios históricos y antropológicos, y propone en este sentido, la creación de una sala de la casa de Austria. La verdad es que el museo, tal y como lo propone Balart, resultaría una auténtica aberración, y en vez de un orden, tendriamos un desorden absoluto. Imaginemos el desoncierto que sentiríamos al entrar a una sala, antes de averiguar si en ella la agrupación de obras se debe al estilo o a la composición.

Madrazo, cuya opinión debía tener más peso como director de la comisión, apostaba sin dudas por el criterio de escuelas, y en todos los documentos a los que he tenido acceso no se plantea que pueda intentarse ningún otro. En una carta de noviembre de 1895, escribe al ministro de Fomento acerca de elio, solicitando además, sorprendentemente, la ayuda de Manuel Villegas Brieva, de la escuela de Bellas Artes de La Coruña, para hacer "los trabajos preparativos» que conduzcan a la ordenación por escuelas ${ }^{14}$. ¿Acaso no tenia Madrazo un conocimiento suficiente de la historia del arte del siglo XIX? En otra carta, de agosto de 1987, expone sus ideas sobre el destino del museo y la influencia de unas escuelas en otras ${ }^{15}$. En realidad, en ningún momento habla de distintas escuelas en España, y diferencia unos momentos de otros según la influencia extranjera que reinara en el país, influencia que parece que consideró en todo momento perjudicial, salvo en lo que contempla como la edad de oro del XIX español, que es, por supuesto, la que vio el reinado de sus familiares y la pintura idealista romántica. Por lo demás, se muestra sumamente reaccionario con las novedades que el final del siglo había traído de la mano de la influencia francesa. En una crítica a la Exposición de pinturas de 1847, celebrada en el Museo de la Trinidad, Madrazo hace una serie de afirmaciones de las que podemos deducir lo que significaba la palabra "escuela" para él: en resumen, viene a ser un sinónimo de "estilo", en la acepción que le daba Mengs en su célebre carta sobre las colecciones reales, de quien sospecho que Madrazo, como continuador de la tradición académica, tomaría la idea de que a cada género, corresponde un estilo según su transcedencia ${ }^{16}$. Recojo

${ }^{14}$ Carta de Pedro de Madrazo al Ministro de Fomento, 19 de noviembre de 1895 Inédita, Archivo General de la Administración.

${ }_{15}$ Carta de Pedro de Madrazo al Ministro de Fomento, 16 de agosto de 1897. Inédita, Archivo General de la Administración.

16 Madrazo, P. de, "Exposición de pinturas de 1847", Semanario Pintoresco Español, 1847, págs. 354-357, 361-364, 388-390. 
sus opiniones porque, al haber llegado a la conclusión de que es muy difícil distinguir auténticas escuelas en la pintura que mereció entrar a formar parte del Museo de Arte Moderno, quizá esta manera de clasificar las obras tuviera alguna influencia en él a la hora de organizar las salas del museo, ya que se empeñó en seguir ese criterio. En 1898, ya en vísperas de la apertura del museo, da en una carta sobre la elaboración del catálogo una breve idea de lo que iba a construir su ordenación por escuelas:

«Entendía esta Dirección que el Museo puesto a su cuidado, convenientemente clasificado por épocas y escuelas, como se ha procurado que esté, era para el hombre estudioso una constante demostración práctica de las interesantes evoluciones que el genio artístico del siglo xIX había llevado a cabo, tomando sus prácticas y doctrinas ya de la escuela romana decadente, personificada en (indescifrable) y otros pintores de igual linage (sic) ya de la francesa del tiempo de la Revolución y del Imperio, fundada por David, introducida en España por Madrazo y Ribera, y tan fecunda en pintores del gusto clásico depurado como Girodes (sic) Gros, Gérard, Ingres, Ri (?) ya por último, y como en el umbral de la edad moderna, de las escuelas románticas francesa, purista e idealista alemana, académica, española, para transformarse en un grandioso sincretismo ecléctico como el que constituye la fisonomía del verdadero arte moderno en todas las naciones en generalı " $"$.

No es de extrañar que, con tan distintas y vagas propuestas entre los miembros de la comisión, el aspecto del museo, cuando se abrió al público, fuese nada diferente al habitual, es decir, con los cuadros colgados según su tamaño, aprovechado el espacio al máximo; parece que la supuesta ordenación por escuelas, tan traida y llevada, no pudo tener correspondencia en la manera en que se colgaron los cuadros, o al menos no resultó evidente a los ojos del público, a juzgar por la lacónica observación del cronista que se ocupó de la inauguración del museo para La ilustración Española y Americana, en el artículo antes citado:

"En ella se ha tenido en cuenta la utilidad del estudio por épocas de las pinturas contemporáneas, y se ha preferido por esta razón un método cronológico».

${ }^{17}$ Carta de Pedro de Madrazo al Ministro de Fomento, 28 de julio de 1898. Inédita, Archivo General de la Administración. 
En la relación de obras que acompaña al artículo, observamos una mezcla de temas y épocas. Madrazo murió poco después de la apertura del museo, y quizá ya estaba enfermo cuando se procedió a colgar las obras, ya que el cronista atribuye dicha tarea a Hidalgo de Caviedes, que quizá no compartiera con Madrazo el criterio de ordenación. No he encontrado ningún dato que pueda confirmar este punto.

De cualquier modo, la carencia de orden hubiera podido ser aliviada en caso de haberse editado un buen catálogo que aclarase la organización de la colección; hay indicios para creer que Madrazo era consciente de la importancia de confeccionar un buen catálogo explicativo ${ }^{18}$, pero a causa de los apremios a que se le sometía, tuvo que conformarse con una ordenación alfabética de autores que sólo incluía los siguientes datos: apellidos, nombre, lugar de nacimiento, maestros, escuelas o academias con los que se formó, premios oficiales, cargos oficiales (profesor, académico, etc...) si los tiene, fallecido (de ser así). Cuadro o escultura: numeración, título, medidas ${ }^{19}$.

\section{EL MUSEO DE ESCULTURA}

Madrazo, de acuerdo con lo que se establecia en el Real Decreto de creación del museo, tenía el proyecto de separar el Museo de Pintura del Museo de Escultura. En dicho decreto, en su primer artículo reza: «El Museo se dividirá en dos secciones, una de Pintura y una de Escultura". Pero en la planta principal no era posible obtener más salas de las que ya iba a ocupar el Museo de Pintura, y, por otra parte, era preferible conseguir espacio en la planta baja, por la dificultad que entrañaba el izar las esculturas más pesadas hasta la planta alta. Pronto tuvo que renunciar a ese proyecto, al denegársele definitivamente el espacio que necesitaba.

La tarea de la instalación de las esculturas debió ser dificultosa. Al apremiarle el Ministro para la apertura del museo, responde Madrazo:

\footnotetext{
18 «Mas para que la simple colocación de los cuadros de principios de siglo por escuelas con frecuencia discordes, no resultase a los ojos del espectador un indescifrable logogrifo, era necesario que un catálogo oficial sirviese de guia al estudioso en la ordenación mental de las obras; y en esta difícil tarea se ocupaba esta Dirección constantemente". Carta de Pedro de Madrazo al Ministro de Fomento, 28 de julio de 1898.

${ }^{19}$ Catálogo provisional del Museo de Arte Moderno, imprenta del Colegio Nacional de sordomudos y ciegos. Madrid 1899.
} 
“Con el propósito de hacerlo así, los industriales con quienes tengo contratados los servicios de traslado de cuadros y estatuas, han recibido el encargo de acelerar sus operaciones, y está ya casi terminado el castillejo por medio del cual han de elevarse los objetos de escultura hasta el piso en cuyo interior han de figurar juntamente con los cuadros. Pero la traslación de los cuadros ha de verificarse antes que la de las estatuas, para que estas no sirvan de estorbo en la colocación de aquellos $[\ldots] " 20$.

La reunión de las esculturas planteó también problemas de peso: se conserva una carta en la que Pedro de Madrazo consulta al arquitecto conservador del edificio sobre la resistencia de los suelos, a propósito de un relieve especialmente pesado, cuya instalación desaconsejó el arquitecto.

\section{SOBRE LA APERTURA DEL MUSEO}

El proyecto del Palacio para la Biblioteca y Museos, sede del Museo de Arte Moderno, pasó por muchas vicisitudes, y el amplio espacio de tiempo que va desde la real orden para su construcción, en abril de 1866, a la apertura final del museo de Arte Moderno, en agosto del 98, año en el que quedó por el momento establecida la repartición del edificio entre los distintos organismos que lo ocuparon, hace que recorriera todos los cambios políticos del último tercio de siglo. Y éste era sin duda un proyecto político, una operación de prestigio y de imagen, como lo son todas estas singladuras todavía hoy y lo serán probablemente en el futuro.

En el caso del Museo de Arte Moderno, partimos de una situación bien conocida: la existencia de una colección de pintura del siglo xıx que, tras el desmantelamiento del Ministerio de Fomento, que había ocupado las estancias del Museo de la Trinidad, se había quedado sin "sede", o mal alojada en El Prado. El estado había hecho, primero con la manutención de la Academia y sus pensionados, y después con el sistema de exposiciones y las consiguientes adquisiciones, un relativo esfuerzo de "protección" a las artes, y era necesario que ese gasto se hiciese evidente a los ojos del público. Digamos que, por el momento, era una inversión que no habia producido todos los beneficios esperables.

${ }^{20}$ Carta de Pedro de Madrazo al Ministro de Fomento, 8 de julio de 1896. 
Sin embargo, parece evidente que el crear un museo de arte no fue la motivación principal del gobierno cuando se decidió la construcción del palacio. Supongo que el modelo a seguir sería el British Museum de Londres, como núcleo de erudición, gran museo arqueológico y biblioteca, aunque, por supuesto, a otro nivel. El Museo de Arte Moderno llega alli un poco de prestado, se instaló el último y tuvo que regatear espacio al Museo Arqueológico y a la Biblioteca Nacional.

El real decreto para la construcción del Palacio de Biblioteca y Museos data del 21 abril de 1866, fecha en la que la reina aprobó el presupuesto, memoria y pliego de condiciones facultativas y económicas para las obras de cimentación, alcantarillado, muros de cerramiento y verja del perímetro. La inauguración de las obras tuvo lugar el mismo día, a las 5 de la tarde. Fue todo un espectáculo; todos lo periódicos recogieron el contecimiento al día siguiente, y en La Gaceta de Madrid se publicó el acta correspondiente. Estuvieron presentes la familia real, O'Donnell, cuerpo diplomático, diputados y demás autoridades. Creo que merece la pena que reproduzca algunos datos que proporcionan las crónicas, que dan idea del carácter del evento. Un "gentío inmenso" ocupaba desde media tarde todos los alrededores del solar de la antigua escuela de veterinaria, más de tres a cuatro mil sillas ocupaban el extenso espacio del solar, todo el perímetro estaba cercado por una empalizada cubierta con un extenso lienzo de los colores de la bandera nacional; en los cuatro ángulos y centro de los costados, elevados mástiles con grandes banderas y escudos, otros más pequeños con banderolas y flámulas y los escudos de armas de las provincias; unía todos los mástiles una guirnalda. En el centro del pórtico, nueve estatuas de las musas. Acompañó el acto una marcha triunfal escrita especialmente por Barbieri para la ocasión, e interpretada por una orquesta de 300 instrumentos por bandas militares ${ }^{21}$. En el cimiento de la columna central de la derecha del pórtico se puso una caja de plomo con varias monedas acuñadas en 1866, un ejemplar de la Gaceta del día anterior y el acta de inauguración, firmada por la reina, los ministros, el gobernador y el alcalde. En La Epoca y El diario español, se reproduce el discurso de Hartzembusch, que intenta enlazar la actividad constructora y de protección a las artes de la reina con la de su abuelo.

Este fue, junto con el de la inauguración de las obras terminadas, el momento en el que se recogieron los frutos de la empresa. Otras personas, los directores de los museos, intentarían después que fuese algo más, pero sin ningún apoyo. Las obras se terminaron en el 92, y hasta

21 La Nación. Madrid, 22-4-66, pág. 4. 
el 94 no se publicó el real decreto que encargaba a Madrazo la organización del Museo de Arte Moderno. He leído varios periódicos de los días posteriores a la inauguración de éste y no he encontrado ninguna reseña sobre ella, ni una palabra. Sólo en la llustración Española y Americana se dio publicidad al asunto. Después de las afirmaciones triunfales sobre la generosidad del estado para con el arte, su preocupación por el arte contemporáneo y demás retóricas, se abandonó el proyecto a su suerte, en un local donde no cabían las obras ni apiñadas, sin unas salas para el Museo de Escultura, sin dotación económica, sin espacio para la restauración, regateándoles cuadros que estaban en los despachos oficiales y sin presupuesto siquiera para la edición del catálogo: el museo se abrió finalmente cuando, tras cuatro años de espera, ya no comportaba un interés ni mediano para la cosa pública. 
